\title{
A possible Late Pleistocene forager site from the Karaburun Peninsula, western Turkey
}

\author{
Çiler Çilingiroğlu ${ }^{1, *}$, Berkay Dinçer ${ }^{2}$, İsmail Baykara ${ }^{3}$, Ahmet Uhri ${ }^{4}$ \\ \& Canan Çakırlar ${ }^{5}$
}

The 'Karaburun Archaeological Survey' project aims to illuminate the lifeways of Late Pleistocene and Early Holocene foragers in western Anatolia. A recently discovered, lithic-rich site on the Karaburun Peninsula offers new insights into a currently undocumented period of western Anatolian prehistory.

\section{The project and site 35}

Since 2015, the 'Karaburun Archaeological Survey' project (KASP) has been generating data on the early prehistory of western Anatolia. A complete lack of information concerning Late Pleistocene and Early Holocene foragers from western Anatolia - and the general scarcity throughout Turkey — creates a data gap that hinders our understanding of forager lifeways or potential forager-farmer encounters in this vast region. The main aim of the KASP is to produce data from pre-Neolithic foragers, and to contribute to the currently debated topics of Aegean and Eastern Mediterranean prehistory. Through the implementation of pedestrian survey methods that record archaeological material from all periods, the project is designed to discover year-round settlements or mounds, as well as evidence for small-scale activity or campsites.

In 2016, pedestrian survey along the south-eastern coastline of the Karaburun Peninsula recorded a 0.3 ha site (site 35) with a relatively intense distribution of human-made chipped stones over Triassic limestone bedrock (Erdoğan et al. 1990). Located on a westeast oriented slope, the chipped stones extended for approximately $80 \mathrm{~m}$ along the shore (Figure 1). The area had good surface visibility with partial covering of evergreen shrubs (Figure 2). A team of nine people surveyed the area in $2 \mathrm{~m}$ transects, collecting over 300 lithics. The only other archaeological find recovered was a corroded Byzantine-era coin.

1 Ege University, Faculty of Letters, Department of Protohistory and Near Eastern Archaeology 35100, BornovaIzmir, Turkey

Ardahan University, Faculty of Humanities and Letters, Prehistory Department, 75002 Ardahan, Turkey

Van Yüzüncü Yıl University, Faculty of Letters, Department of Anthropology, 65080 Van, Turkey

Dokuz Eylül University, Faculty of Letters, Department of Archaeology, 35260 Buca-Izmir, Turkey

Groningen Institute of Archaeology, Poststraat 6, 9712 Groningen, the Netherlands

Author for correspondence (Email: ciler.cilingiroglu.unlusoy@ege.edu.tr)

(C) Antiquity Publications Ltd, 2018

ANTIQUITY 92 362, e2 (2018): 1-5

https://doi.org/10.15184/aqy.2018.51 


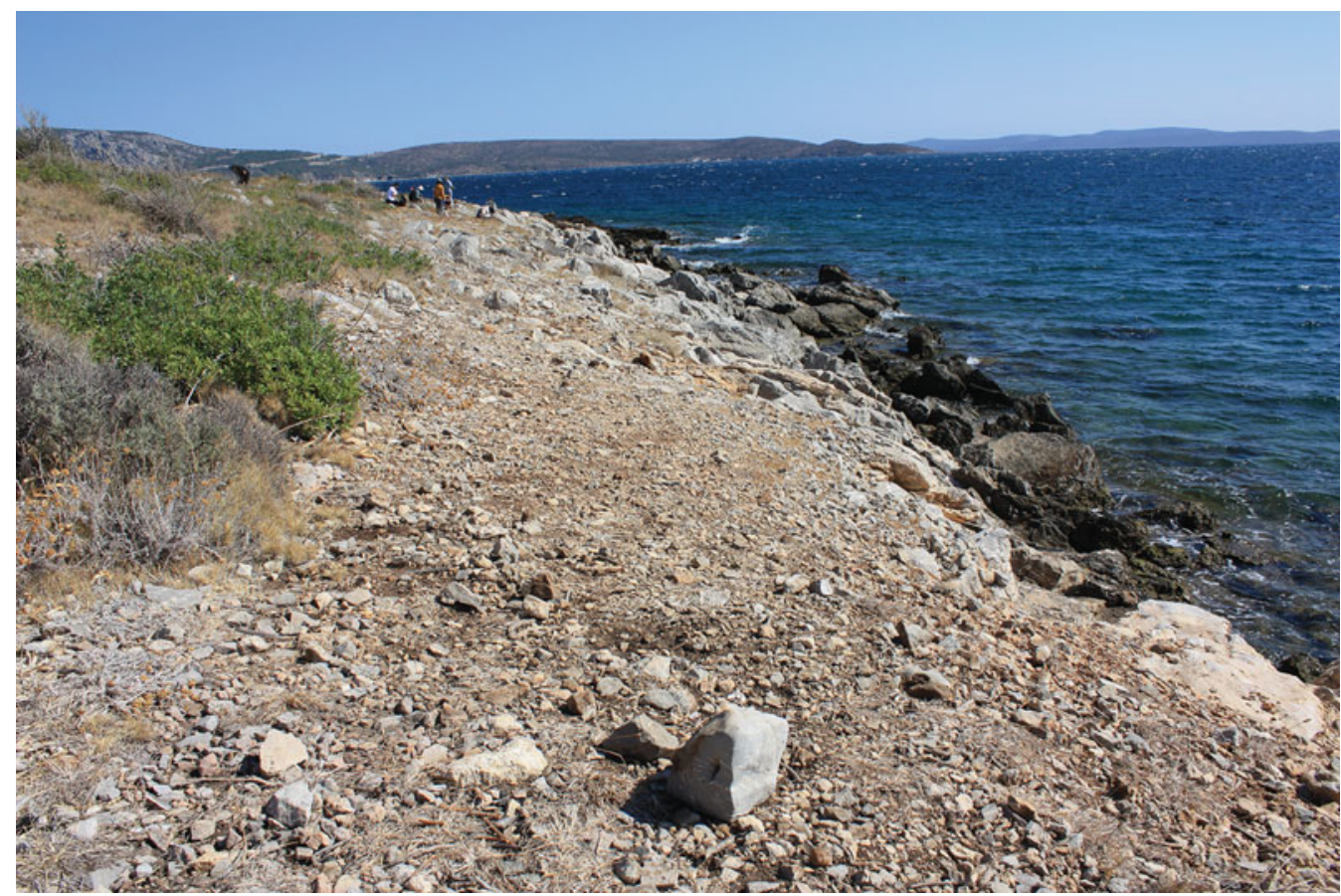

Figure 2. General view of site 35 from the south (photograph by Ç. Çilingiroğlu).

\section{The chipped stones from site 35}

The chipped stones comprise almost entirely white-patinated chert (originally dark grey), although red, pink, orange and grey patinas are also visible on some pieces. The quality of the raw material is mainly normal to poor, with good quality material recorded only on 47 pieces. Cortical pieces are rare in the assemblage $(n=46)$, indicating that the raw material sources are not located close to the site and that early stages of reduction took place elsewhere.

Of the 26 cores identified in the assemblage, eight are blades or bladelet cores. The cores are highly reduced and microlithic in character, with lengths ranging from $16-29 \mathrm{~mm}$ and widths from $10-39 \mathrm{~mm}$. Nearly half of all the identified blanks at the site are flakes $(\mathrm{n}=$ $180)$, and around 16 per cent of the whole assemblage comprises blades and bladelets ( $\mathrm{n}=$ 57). The sizes of the blanks are also microlithic in scale, with flakes measuring $6-28 \mathrm{~mm}$ in length, and blades measuring $6-33 \mathrm{~mm}$ in length.

Among the blanks, only 52 pieces show signs of retouch, constituting 14 per cent of the entire assemblage. Retouched pieces are further classified according to their tool types. Among these are side-scrapers $(n=4)$, end-scrapers $(n=10)$, retouched flakes $(n=21)$, retouched blades $(n=6)$, notches $(n=2)$, a burin, a perforator, a lunate and a composite tool (in this case, a tool with three different kinds of retouch on its three sides) with a denticulated edge. Tools mainly exhibit scalar, fine, marginal, abrupt and stepped retouch (Figures $3 \& 4$ ). 

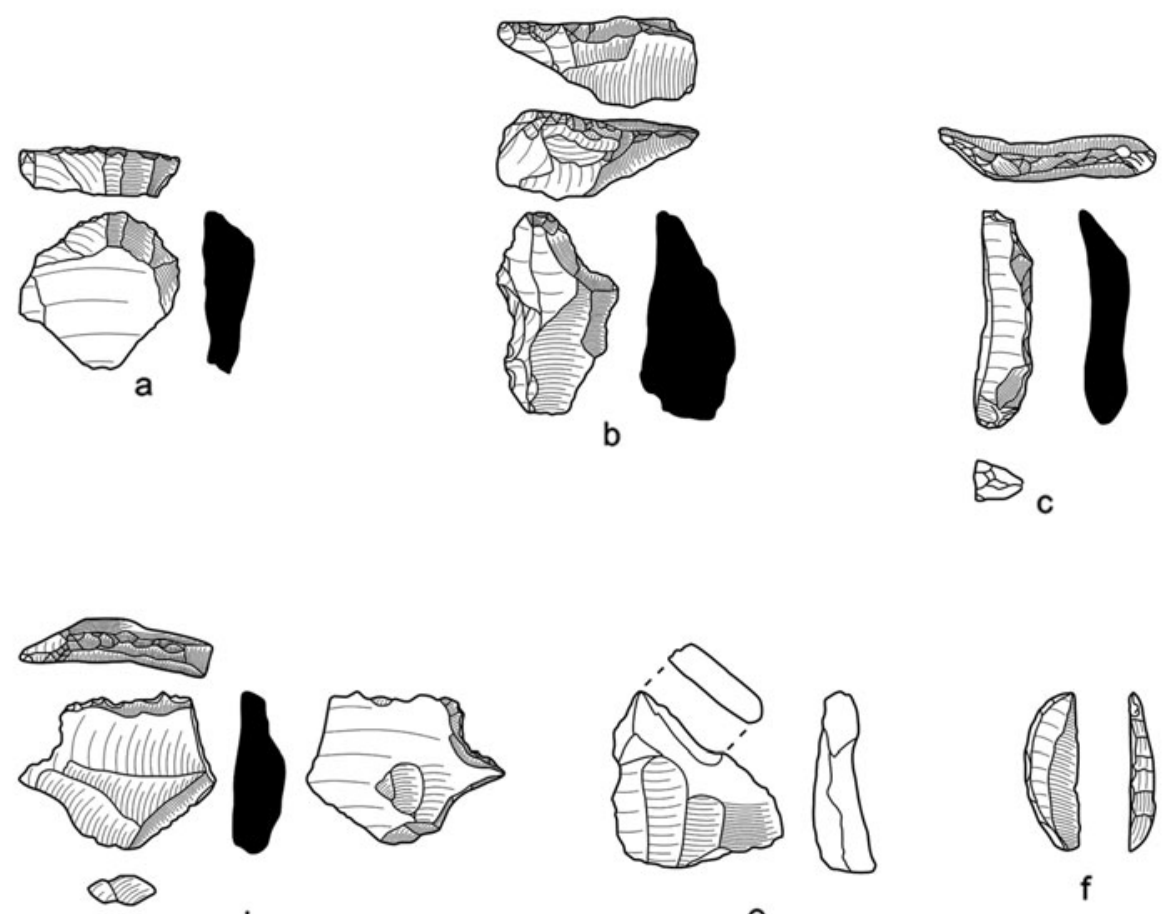

d

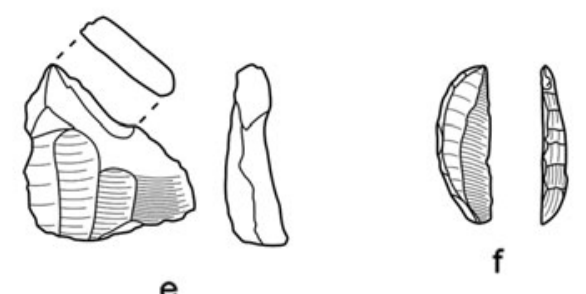

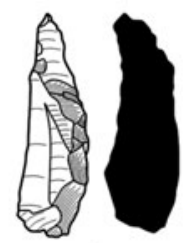

g

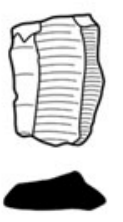

$\mathrm{h}$

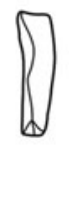

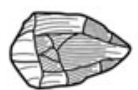
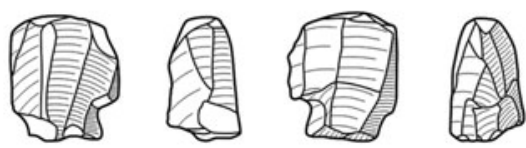

i

Figure 3. A selection of chipped stones from site 35: a-c) scrapers; d) perforator; e) burin; f): lunate; $g-h$ ) retouched blades; i) bladelet core (drawing by D. Turan).

\section{Discussion}

The microlithic character of the assemblage and the relatively large proportion of blades and bladelets contrast with an open-air site (site 31) discovered previously by the KASP, which was tentatively assigned to the Aegean Mesolithic tradition (Çilingiroğlu et al. 2016; Çilingiroğlu 2017). The very small size of the cores and the presence of microlithic flakes and bladelets-as well as geometric pieces such as the lunate-from site 35 allows for (C) Antiquity Publications Ltd, 2018 
general comparisons with the "flake-bladelet industries" of Pleistocene/Holocene Epigravettian tradition (Kaczanowska \& Kozłowski 2014: 35). Moreover, some typo-technological similarities can be identified with the Final Pleistocene site of Ouriakos on Limnos, where lunates only comprise a very small (1.25 per cent) portion of the site's
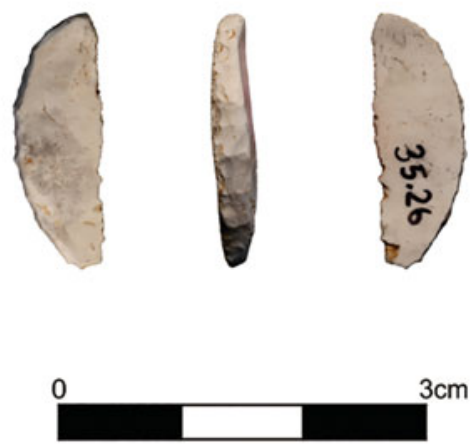

Figure 4. The single lunate from the site 35 assemblage (photograph by C. Bayak).

clearer assessment of the site and its date. assemblage. The size of the site 35 lunate (Figures $3 \& 4$ ) is also very similar to that of the Ouriakos lunates, which are 12-22mm long and 2.3$3.5 \mathrm{~mm}$ thick (Efstratiou et al. 2014: 6). Based on our preliminary observations and available comparative material from the eastern Aegean, we propose that site 35 was a short-term, Late or Final Pleistocene, forager site. In the absence of comparative sites from western Anatolia and absolute dates from site 35, this suggested dating remains tentative at best. Future studies should provide a

\section{Acknowledgements}

The project is conducted with the permission of the Turkish Ministry of Culture and Tourism, and is supported by the Ege University Research Fund (grants: 2015-EDB-005; 2016-EDB-018), Groningen University Institute of Archaeology and the Municipality of Karaburun.

\section{References}

ÇiLingiroĞLu, Ç. 2017. The Aegean before and after $7000 \mathrm{BC}$ dispersal: defining patterning and variability. Neo-Lithics 16: 32-41.

Çilingingŏ́lu, Ç., B. Dinçer, A. Uhri, C. GürbiyiK, İ. Baykara \& C. ÇaKirlar. 2016. New Palaeolithic and Mesolithic sites in the eastern Aegean: the Karaburun Archaeological Survey project. Antiquity Project Gallery 90(353).

http://dx.doi.org/10.15184/aqy.2016.168
Efstratiou, N., P. Biagi; \& E. Starnini. 2014. The Epipaleolithic site of Ouriakos on the island of Lemnos and its place in the Late Pleistocene peopling of the East Mediterranean region. Adalya XVII: $1-24$.

ErdoĞan, B., D. Altiner, T. Güngör \& S. Özer. 1990. Karaburun Yarımadasının Stratigrafisi. Maden Tetkik ve Arama Dergisi 111: 1-23.

Kaczanowska, M. \& J. K. KozŁowsKi. 2014. The Aegean Mesolithic: material culture, chronology, networks of contacts. Eurasian Prehistory 11(1-2): 31-62. 